\title{
Introduction
}

\section{UK's Membership of the EU: Brexit and the Gains, Losses and Dilemmas for Social Policy}

\author{
Ania Plomien \\ London School of Economics and Political Science \\ E-mail: a.plomien@lse.ac.uk
}

The United Kingdom has a long history of a fraught relationship with the European Union, a discomfort demonstrated in the 23 June 2016 referendum on the membership of the EU, in which the UK voted to leave with nearly 52 per cent majority vote. Among the key concerns underlying UK's unease with EU are the interrelated areas of the economy, polity, and society. However, public debate surrounding the event focused on a relatively narrow range of issues. The two official campaigns representing the choice in the referendum, 'Vote Leave, take control' and 'Britain Stronger in Europe', were marshalled either to support Eurosceptic feelings or to emphasise the benefits of access to the Single Market. Commonplace convictions that the $\mathrm{EU}$ is responsible for that which is negative, inconvenient, or difficult to explain circulated alongside (though less frequently than) the recognition of the economic privileges and opportunities that come from EU membership. The political, economic and social concerns were encapsulated in themes of taking power back from Brussels, redirecting resources from the UK's contributions to the EU budget towards nationally determined projects (most famously allocating $£ 350$ million a week for the National Health Service), and effective border control to significantly curb migration. Contradictory claims about the EU and the UK's affiliation with it were further complicated by the fact that divisions over the support for or opposition to Britain's withdrawal spanned the whole political spectrum.

The aim of this themed section of Social Policy and Society is to explore the impact the EU social policy has had on the UK to date, to examine what role the UK has played in shaping EU-level developments, and to consider the implications of Brexit for UK social policy development after leaving the EU. The authors who have contributed to this themed section have not taken Brexit - the UK's decision to hold a referendum and the vote to leave - as their main problematic. This theme has been explored elsewhere (see Becker et al., 2016; Goodwin and Heath, 2016; Guerrina and Murphy, 2016; Vasilopoulou, 2016; Jessop, 2017) and will likely be pursued in future research. Instead, the objective was to take Brexit as an analytical starting point and a context to understand the meaning of the EU for the UK, the role that the UK has played in the EU, and what Brexit will mean for the UK with respect to potential gains, losses, and dilemmas. The forward-looking perspective, however, is necessarily grounded in current and past events delineated by national and EU borders. Engaging with the implications of Brexit thus posed significant challenges throughout the research, analysis and writing of the articles in this themed section. The obvious difficulty concerns the timing and the lack of clarity provided by Brexit negotiators, especially on the UK side, about their goals and objectives. Changes in 
the direction of the political winds, therefore, pose a risk to the analysis at hand. However, the risk of not engaging with the topic is even greater. Undoubtedly, Brexit represents a major national and international political development, and a better understanding of its social dimension is necessary for articulating appropriate responses.

A related challenge concerns the scope of the analysis included in this themed section and the representation of voices and concerns of different population groups which will be affected by Brexit. The contributors engage with the problem of inequality from the macro level of supranational and national policy making. The five original research articles engage with various dimensions and levels of social policy, in turn emphasising the long-standing relationship between the UK and the EU, the development of social and gender policy at the EU level, the importance of the EU gender equality framework to employment and social policies in the UK, the consequences of the gendered process of the UK withdrawing from the EU, and the UK's approach to migration in relation to social and economic objectives. These themes reflect the concerns and expertise of the contributing authors working from different analytical and disciplinary perspectives. The final composition of authors and articles in this section is an outcome of a combination of factors, including a deliberate attempt to combine wide representation with a coherent substantive and analytical focus and the availability of all who were invited to take part in this project. The resulting accounts on the UK-EU relations, on the development of specific policies in the EU and their significance to the UK, and the construction of migration processes and policies, are therefore selective, and important gaps remain. Attention to gender focuses on working parents, attention to women centres on working women (and often mothers), and attention to migrants emphasises the high- and low-skilled, and those from within or outside the EU. There is considerable scope to incorporate other axes of power and inequality, which will make a difference to how Brexit is experienced by those concerned. Such is already being carried out (see for example Burnett, 2017; Ellison, 2017; Kilkey, 2017; Meer, 2017; Netto and Craig, 2017), and the analyses provided in this themed section cannot be interpreted in isolation from such intersectional concerns.

The final challenge of engaging with the problematic of Brexit and its implications for social policy development in the UK is a dilemma, often faced by progressive and feminist researchers and activists: namely, how to reconcile a critical stance with practical action for change, especially if such are not neatly aligned? These are not new questions for feminist scholars considering social policy and addressing the welfare state (Fraser, 2009; Funk, 2013; Orloff and Shiff, 2016). The majority of the authors in this themed section have contributed independent research and expertise to the UK and EU policy processes and have engaged with policy makers and parliamentarians in the national and supranational contexts. These activities, to some degree, have shaped their analyses and insights. All the articles in this themed section on Brexit raise serious concerns over the past and current state of social and gender policies and patterns in the EU and note fundamental shortcomings in the way that the EU has approached the rights and wellbeing of people across the continent. Nevertheless, the authors concur in their scepticism about the UK's withdrawal from the EU and what it means for the development of the social dimension in domestic politics, although are less pessimistic in their views of the implications Brexit will have for the EU. Both predictions will be put to the test in the coming months and years. The former, however, seems more likely. Although none of the authors can say with certainty and precision what Brexit will mean - despite repeated assertions by the British Prime Minister Theresa May that 'Brexit means Brexit' - we did not identify any 
meaningful gains of this process, if only because the overarching reasons for why the UK in the end opted to leave the EU were anything but progressive. Regarding the second, it is not clear that UK's departure from the EU will make matters easier for social and gender progress in Europe. Whilst the UK and EU interacted bi-directionally, policy download was accompanied by policy upload; as well as its watering down and blocking, Brexit will therefore change policymaking in Brussels and Strasbourg by excluding a difficult policy negotiating partner. But, the EU will also lose a powerful member, which weakens the EU internally as well as externally regarding political, economic, and social domains. This is one of the big unknowns of Brexit.

The articles in this themed section engage with a closely related range of issues. Setting the scene, Linda Hantrais reviews the key dimensions and events comprising the over four-decade long relationship between the UK and the EU, highlighting the significance of the past to the future developments of EU and UK social policy. The longterm view adopted in the article reveals the reciprocity characterising the interactions between the EU and UK political actors and institutions and their role in influencing the politics and policies at the economic and social nexus. The UK joined the Union in 1973, at a time when social issues gained importance vis-à-vis economic integration, and so the UK weighed in on the contours of the social from very early on. The respective governing parties shaped the character of the national influence to a great extent, with Labour being more engaged with and receptive to the EU social dimension than the Conservatives. Hantrais' analysis also illuminates how the member state-EU dichotomy is not always the most appropriate lens through which to assess membership in the Union, as the UK's contribution of individual experts and policy makers serving across the EU structures of governance and acting on behalf of the EU makes clear. Framework agreements reached between social partners on a raft of social measures further complicate a dichotomous UK-EU view. Finally, the article points to the scope, quality and quantity of hard and soft law policies developed over time and variously incorporated into the UK legal framework, primarily concerning the rights of workers. These key themes developed by Hantrais the reciprocity between the UK and the EU, the role of UK political actors within the EU institutions and that of social partners for policy development, as well as the breadth and depth of policies in place - show just how embedded the UK has become in the EU and how complex Brexit is likely to be.

The next article, by Ania Plomien, extends the discussion of the EU level social dimension by focusing on gender and analysing the most recent developments in EU social and gender policy unfolding since the new European Commission took power in 2014. The new emphasis on social and gender policy in the EU comes in the form of the European Pillar of Social Rights proclaimed in November 2017 in Gothenburg. As Plomien argues, this certainly is a welcome, if still insufficient, development from the perspective of social and gender justice. Plomien's analysis demonstrates that the time for a renewed focus and action on social and gender issues is high. There are (at least) two interrelated reasons for this urgency. First is that, while the EU has an extensively developed social acquis, its record on social and gender policies has been mixed. These policies have contributed towards strengthening the social rights of workers and towards women's equality in economic, social, and political life but, as the literature demonstrates, the social has been subordinate to the economic and gender deployed towards meeting other policy goals. The second motivation for attending to social and gender issues is the current state of social Europe - grappling with the persistence of complex inequalities and 
stalled or slow progress on their many dimensions, especially since the global economic crisis, the EU leaders had no choice but to act. The Pillar raises the visibility of the social and gender dimensions, and, through measures like those on work-family balance, it proposes concrete solutions extending current EU level provisions. The fates of the Pillar and of Brexit are, to some extent, interrelated. A broadening and deepening of the EU social domain represents a loss to the UK, which will not take part in the shaping of that process and in its post-Brexit implementation. Equally, Brexit poses a risk to the development of the Pillar as the political, symbolic, and material resources required to put the social at the top of EU policy agenda will have to compete with managing Brexit.

In the third article, Colette Fagan and Jill Rubery focus on the gender equality framework in employment and demonstrate how a two-way relationship between the EU and the UK has developed in this policy area. The authors argue that, because of incomplete gender mainstreaming of EU employment policies, these policies bring many contradictions and tensions from the perspective of progressing on gender. This is seen, for example, in pursuing labour market flexibility policies and restraining minimum wage demands as if taking place in isolation from intentions to eradicate the gender pay gap. At the same time, however, the $\mathrm{EU}$ has been at the forefront of championing gender mainstreaming and has achieved significant progress, especially up to the late 1990s. Furthermore, in an under-regulated context like that of the UK, as well as in the countries joining the EU through its several enlargements, Europeanisation of equality measures has proven immensely important for strengthening domestic provisions. In the UK, this has been the case through hard and soft law, and has influenced progressive employment and social policy reforms including in childcare and work-family balance, in addressing the gender pay gap, and encouraging targets for corporate boards. The domestic context is clearly important in how EU imperatives are implemented on the ground, with the New Labour, although not itself a champion of social Europe, pursuing gender equality in employment and in social policy more extensively than other governments. Finally, Fagan and Rubery also note an important potential loss for the UK in terms of knowledge about gendered patterns and policies - a crucial element in the process of reforming employment and social policies and a resource for analysts as well as activists. These dimensions lead them to conclude that Brexit will be detrimental to gender equality developments in the UK.

In agreement with the previous article, Roberta Guerrina and Annick Masselot demonstrate that the UK gender equality legislation is grounded in EU social law. They argue that the UK government's inattention to just how much domestic law is entrenched in the framework of EU regulations poses a serious threat to all those who have benefited from these regulations. Such side-lining of social and gender issues is plausible given the government's pursuit of austerity policies which had a disproportionately negative impact on variously positioned women. Economic crises are likely to reinforce, rather than challenge, marginalisation of social and gender issues vis-à-vis interests of businesses. Furthermore, any post-Brexit scenarios are considered by drawing on the existing track record of the UK government on gender equality policy. Guerrina and Masselot analyse two case studies - maternity rights and gender diversity in economic leadership - to draw out the implications of Brexit on the gender regime in the UK after it leaves the EU. These two examples show the UK government's commitment to business rights over women's rights on the domestic and EU arenas, which have contributed to the weakening of EU provisions. Guerrina and Masselot contend that the UK's existing gender regime of minimum standards will break down without the support from the EU. 
Unlike all the other authors in this themed section, Alessio D'Angelo and Eleonore Kofman engage with a theme that has been very prominent in the run up to the referendum and in the negotiation talks - migration. This allows the authors to trace the contours of the referendum debates and place them in the context of UK's migration regime. D'Angelo and Kofman frame their discussion of migration as a policy of controlled management of mobile workers who temporarily fill in the labour market sectors with skill and labour shortages, rather than a system prepared for fully accepting migrant workers into the UK society. The 2004 enlargement of the EU and the ensuing large-scale migration of workers from Central and Eastern Europe, many of whom settled in the UK, have put that principle to the test. D'Angelo and Kofman argue that the attitudes towards EU migrants must be interpreted in the wider context of apprehensions over high immigration as well as in relation to Euroscepticism, both long-standing issues that had been exploited in the referendum debates. Among the key themes are: impact of migrant workers on labour markets regarding downward pressures on wages, displacing local workers in competition for jobs and straining public services. Despite the prominence of migration surrounding Brexit, the rights of EU citizens in the UK after Brexit have not been resolved at the time of writing. Positioning EU migrants similarly to non-EU migrants is among the proposed government solutions, a development that would deteriorate their and their family migration rights. But, as D'Angelo and Kofman argue, UK's economic interests at least in the immediate future are linked with according rights to existing EU citizens in the UK - showing the interdependence of social and economic spheres.

As all the articles in this themed section demonstrate, the UK's membership of the EU has been important for policy development in the UK as well as in the EU, and the implications of Brexit, although difficult to predict exactly, do not bode well for social progress on the domestic scene. The incomplete and unanswered aspects of Brexit indicate that the debate over this event will continue. There are numerous ways in which the debate should be taken forward, including understanding the content and the character of the event itself, as well as the complex reasons for its emergence and the no less clear consequences once the negotiation process is completed and its agreements implemented. We hope that developing the themes of causes, dimensions, and consequences of Brexit will build on our partial account and engage with it; not for the sake of Brexit as a discrete event, but for what it represents - a deep underlying crisis of the social and its political and economic dimensions.

\section{Acknowledgments}

I would like to thank all the anonymous peer reviewers for their time, expertise and constructive comments provided to the authors. I am particularly grateful for the reviewers' collegiality given a tight timeline for producing this themed section. I would also like to thank the editorial team of Social Policy and Society - Liam Foster, Majella Kilkey, and Shona Kirk - for their intellectual and professional guidance.

\section{References}

Becker, S., Fetzer, T. and Novy, D. (2016) Who Voted for Brexit? A Comprehensive DistrictLevel Analysis, CCAGE, University of Warwick WP no 560, http://ukandeu.ac.uk/wp-content/ uploads/2016/10/Who-voted-for-Brexit.pdf [accessed 30.11.2017]. 
Burnett, J. (2017) 'Racial violence and the Brexit state', Race and Class, 58, 4, 85-97.

Ellison, M. (2017) 'Through the looking glass: young people, work and the transition between education and employment in a post-Brexit UK', Journal of Social Policy, 46, 4, 675-98.

Fraser, N. (2009) 'Feminism, capitalism and the cunning of history', New Left Review, 56, 97-117.

Funk, N. (2013) 'Contra Fraser on feminism and neoliberalism', Hypatia, 28, 1, 179-96.

Goodwin, M. J. and Heath, O. (2016) 'The 2016 referendum, brexit and the left behind: an aggregate-level analysis of the result', The Political Quarterly, 87, 3, 323-32.

Guerrina, R. and Murphy, H. (2016) 'Strategic silences in the Brexit debate: gender, marginality and governance', Journal of Contemporary European Research, 12, 4, 872-82.

Jessop, B. (2017) 'The organic crisis of the British state: putting Brexit in its place', Globalizations, 14, 1, 133-41.

Kilkey, M. (2017) 'Conditioning family-life at the intersection of migration and welfare: the implications for 'Brexit families", Journal of Social Policy, 46, 4, 797-814.

Meer, N. (2017) 'What will happen to race equality policy on the Brexit archipelago? Multi-level governance, 'sunk costs' and the 'mischief of faction", Journal of Social Policy, 46, 4, 657-74.

Netto, G. and Craig, G. (2017) 'Introduction: migration and differential labour market participation', Social Policy and Society, 16, 4, 607-61.

Orloff, A. S. and Shiff, T. (2016) 'Feminism/s in power: rethinking gender equality after the second wave', in A. S. Orloff, R. Ray and E. Savci (eds.), Perverse Politics? Feminism, Anti-Imperialism, Multiplicity, 30, 109-34.

Vasilopoulou, S. (2016) 'UK Euroscepticism and the Brexit referendum', The Political Quarterly, 87, 2, 219-27. 